\title{
Influence of moisture absorption on the flexural properties of composites made of epoxy resin reinforced with low-content iron particles
}

\author{
E SIDERIDIS*®, J VENETIS®, E KYRIAZI and V KYTOPOULOS \\ School of Applied Mathematics and Physical Sciences, Section of Mechanics, NTU Athens, 15773 Athens, Greece \\ *Author for correspondence (siderem@mail.ntua.gr)
}

MS received 8 July 2015; accepted 14 October 2016; published online 27 July 2017

\begin{abstract}
In this work, the effect of moisture absorption on the mechanical properties of particulate composite materials is studied. Moisture absorption constitutes a main parameter affecting the thermomechanical behaviour of composites, since it causes plasticization of the polymer matrix with a concurrent swelling. In the present work, the influence of water absorption on the flexural properties of particle-reinforced composites was thoroughly investigated. It was found that during the process of moisture absorption there exists a variation of the flexural properties closely related to the degradation of the mechanical behaviour of the composite, as well as the percentage amount of moisture absorbed. Experiments were carried out with composite made of epoxy resin reinforced with low-content iron particles. The variation of ultimate stress, breaking strain, deflection, elastic modulus and Poisson ratio due to water absorption was examined.
\end{abstract}

Keywords. Particulates; composites; moisture absorption; flexural properties.

\section{Introduction}

Particulate composites are composites reinforced with particles, where all dimensions show the same order of magnitude. They are produced from a matrix, usually polymer, into which a suitable pulverized substance has been dispersed.

Evidently, such composites are not usually considered as 'precious' since they cannot reach the strength and stiffness of fibre-reinforced composites and therefore they are not used in high-tech applications, such as aircraft and space constructions. During the last years, significant progress has been achieved in applications with various types of fibres and other types of matrix such as metal matrix or ceramic matrix, which can serve for example at high temperatures. Thus, from this point of view this material cannot be characterized as a new since epoxy resin and iron particles are not 'modern' materials.

However, this type of composite can be used in various applications that do not need high stiffness and strength. On the other hand it can serve as a material for basic research, given that the results of an experimental research work carried out with particulate composites in hygrothermal conditions may be compared to experimental data that will be carried out with new materials in the future, whenever it is possible. Various thermomechanical properties of particlereinforced composite materials are strongly impressed by moisture absorption [1]. Many composite materials of this type have been formed in order to increase the thermal conductivity and the thermal expansion coefficient and to decrease the damage of the matrix. Thus, metallic powder as inclusion in a matrix of thermosetting epoxy results in the creation of a composite material that is more 'powerful' and resistant and easier transfer of heat and electricity than in the matrix alone. It is known that the addition of copper particles in epoxy resin augments the electrical conductivity of the resin very much. Also, the existence of particles increases the viscosity. Generally, particles with small dimensions augment this aforementioned property more, although this observation does not constitute a general rule. In addition, the thermal stability is enhanced by the presence of particles. Besides, the resistance to compression is increased on adding metal particles, due to their stiffness. The same result is obtained for the impact resistance. The surface hardness, the friction resistance and the quality of mechanical machining are improved by the incorporation of metal particles in epoxy resin. Meanwhile, the inclusions, which generally diminish the degree of contraction, effectively increase the adhesion ability of the epoxy resins. Yet, the particulates, the majority of which have higher density than that of the resin, increase the density of the composites. Thus, their existence considerably diminishes the overall cost of the composite. Finally, as to the resistance to moisture, the particulates generally reduce the diffusion speed of water in the composite. Also, the particulates participate in the corrosion of polymers when they contact metals. Ions that possibly exist in a resin with amine can transport currents and thus favour the corrosion. Epoxy resin hardened with amine has less conductivity than that of the resin reinforced with particulates. 
This increment is due to the ability of particulates to release ions. On the other hand, it seems that the main shortcoming of particulates is that they decrease the tensile strength and the ultimate strain, at normal temperatures, as well as the bending strength. Yet, although they augment the tensile modulus and bending modulus this increase is not as significant as that obtained by fibres. Apart from these, absorbed moisture brings on plasticization of the polymer matrix with a simultaneous swelling and decrease of its glass transition temperature, which is referred to as $T_{\mathrm{g}}$ [2-5]. Thermal expansion and swelling of a composite due to temperature and moisture variations influence significantly the mechanical properties of its constituents, through residual stresses between the fibre and matrix [6]. Moreover, incorporation of fillers into polymeric matrices leads to changes in their glass transition temperature $T_{\mathrm{g}}$ [7], probably because of the immobilization by absorption of polymer segments close to the surface of the filler particles [8]. Some discrepancies were also detected in the determination of the effect of the filler content on $T_{\mathrm{g}}$. Some authors have found a linear relationship between increasing filler content and increasing $T_{\mathrm{g}}$ [8], whereas others have found that $T_{\mathrm{g}}$ is not affected appreciably by the filler content [9-11].

In previous research works carried out in Strength of Materials Department of NTUA, it was found from dilatometric [12] and calorimetric measurements [13] that $T_{\mathrm{g}}$ values of metal-filled epoxy composites were strongly dependent on the filler volume fraction and, in some cases, a decrease with the amount of filler was pointed out. Also, a parameter that affects the position of transition temperature in thermal measurements is the heating rate. Considerable differences were observed in differential scanning calorimetry (DSC) measurements depending on the heating rate [13,14]. Furthermore, moisture diffusion characteristics in epoxy components are crucial factors for predicting the mechanical response and durability of epoxy components in a given environment [15]. The second Fick's law of diffusion may be successfully applied to evaluate sorption and desorption of moisture in epoxy composites [16-19].

On the other hand the mechanical properties of epoxy composites depend, amongst others, on the nature of filler and matrix, the strength of the bond between fillers and the surrounding matter of matrix or their mutual adhesion efficiency, the filler content, the size and size distribution of the fillers, the shape of the inclusions, the fabrication method and the conditions of use. Concerning the latter, it is well known that immersion of composite materials into aqueous environments results in a degradation of their thermomechanical properties. This phenomenon is related to the moisture-induced plasticization and/or micromechanical damaging such as interfacial damage [20] and matrix cracking [21,22].

The dual action of absorbed water as a plasticizer and a crazing agent as well deteriorates, in a different way, the physical and mechanical integrity of the epoxy matrix material. This is because plasticization process is indeed a reversible procedure compared with microcavitation damage, which is a permanent one. Especially, for the latter it was found that water absorption influences the adhesion efficiency between filler and matrix as well as the extent of boundary interphase developed in the area surrounding each inclusion [23]. The concept of boundary interphase and its effect on the overall thermomechanical properties of epoxy composites has been described and studied in a series of previous papers $[12,13,23,24]$. This area has been developed because of the restriction of the segmental mobility of the macromolecules of the matrix due to their adsorption onto the filler surface and is featured by structural microdefects such as impurities, microcracks, voids, etc. as well as by concentration of stresses. In the case of water absorption, the action of water results in the partial disruption of the bonds between filler and matrix and the formation of additional cavities, which could be filled with water. Weitsman and Guo [25] established a correlation between fluid-induced damage and anomalous fluid sorption in polymeric composites, whereas Hiel and Adamson [26] studied the thermal expansion and swelling of cured epoxy resin used in composite materials due to temperature and moisture variations that typically occur in a launch environment. In this significant work it was shown that constitutive equations for moisture absorption and moisture-induced dimensional changes can be obtained by means of an internal variable method on the basis of irreversible thermodynamics theory. Moreover, Bera et al [27] investigated the effects of thermal shocks and thermal spikes of hydrothermal behaviour of composites. Blikstad et al [28] studied the long-term moisture absorption in fibre-reinforced composites. Apicella et al [29] investigated the environmental degradation of the electrical and thermal properties of organic insulating materials, whereas Apicella and Nicolais [30] investigated the environmental ageing of epoxy resins. Verpoest and Springer [31] evaluated the moisture absorption characteristics of aramid epoxy composites. Cai and Neitsan [32] examined the non-Fickian moisture diffusion in polymeric composites. Woo and Piggott [33] studied the water absorption of resins and composites. Meanwhile, Weitsman [34] thoroughly studied the moisture transport in fibre-polymer composites. Besides, Xiang and Jones [35] investigated the thermal-spike-enhanced moisture absorption in carbon fibre composites. Moreover, Park and McManus [36] worked on thermally induced damage in composites, whereas Popineau et al [37] studied the free/bound water absorption in an epoxy adhesive.

In the recent years, a remarkable extent of research work has been carried out towards the determination of mechanical properties of advanced particle and fibre composite materials in moisture conditions. In particular, Ozdemir and Mengeloglu [38] investigated the adhesion strength in a category of particulate composite panels made from wood flour and recycled polyethylene, and proposed a method to reduce the water absorption and thickness swelling of the panels. Also, the variation of fundamental mechanical properties such 
as tensile, flexural and impact strengths of a large class of polyester hybrid composites reinforced with randomly oriented natural fibres was thoroughly examined by Athijayamania et al [39]. In addition, the elastic modulus of laminate composites, whose panels were made by coconut fibre particles using castor oil polyurethane adhesive, was determined by a three-point bending test [40]. In this significant study, the specimens were soaked in water for a period of 2 and $24 \mathrm{~h}$. Besides, the influence of moisture absorption on the flexural properties of vinyl ester matrixglass particle synthetic foams was investigated by Tagliavia et al [41]. In this work the flexural properties are identified through three-point bending tests conducted on four types of synthetic foam compositions containing micro-balloons of 220 and $460 \mathrm{~kg} \mathrm{~m}^{-3}$ true particle density in 30 and 60 vol\% of particles. A one-dimensional Fickian model is used to identify the diffusion parameters from short-term moisture absorption of neat vinyl ester resin and synthetic foams. On the other hand, Alok et al [42] obtained an amendment of tensile strength and flexural properties of epoxy resin composites in water, compared with non-reinforced samples. These workers used shell powder of several particle sizes and contents to reinforce the matrices, a fact that amplifies the interfacial bonding between filler and matrix and reduces the number of micro-voids, resulting therefore in a decrement of the water absorption. In this study, long-term water immersion method was used to determine the absorption behaviour of the samples. The conditioned composite samples were placed in a beaker with water at $23 \pm 1^{\circ} \mathrm{C}$. At the end of $24 \mathrm{~h}$ one of the samples was removed from the water at a time, all surface water wiped off with a dry cloth, weighed immediately and then replaced in the water; this procedure was repeated every $24 \mathrm{~h}$ for 7 days and the data were recorded. Concurrently, Bhaskar and Singh [43] investigated experimentally the influence of water absorption on the compressive strength of natural filler particulate composites (coconut shell particle). The effects of water absorption were observed after $24 \mathrm{~h}$ of soaking. In this work, the water absorption capacity was found to have its maximum value for $30 \mathrm{wt} \%$ of coconut shell particle. The maximum compressive strength investigated was $88.0 \mathrm{MPa}$. The optimum combination was $30 \mathrm{wt} \%$ reinforcement of 200 $800 \mu \mathrm{m}$ coconut particle in terms of water absorption and compressive strength. Hamim and Singh [44] discussed the effect of hygrothermal ageing on the mechanical properties of fluorinated and non-fluorinated clay-epoxy nanocomposites. Specifically, these researchers determined the extent of permanent degradation of fracture and flexural properties due to the hygrothermal ageing by drying the epoxy and their clay-epoxy nanocomposites after moisture absorption. This study was conducted to elucidate the effect of moisture absorption on the mechanical properties of clay-reinforced epoxy polymers. Fracture toughness, flexural strength and flexural modulus were determined for two different clayepoxy nanocomposites following the ASTM standards. The effects of hygrothermal ageing and subsequent redrying on the mechanical properties of these polymer nanocomposites were investigated. After removing the free water by drying, the irreversible effect or the permanent damage due to hygrothermal ageing on the clay-epoxy nanocomposite systems was determined. Irrespective of the clay reinforcement type, all the studied properties degraded due to hygrothermal ageing. Also, Hossain et al [45] investigated the effects of wood properties on the behaviour of wood-particle-reinforced polymer composites. It was found that water absorption of both pure polyester and wood-particle-reinforced composites increased with time. Nevertheless, the overall water absorption behaviours of the composites are dependent on the density of the wood used. Water absorption test of the developed composites was carried out according to ASTM D570 at ambient temperature. To do this, specimens were immersed in water bath for 4 weeks at ambient temperature. After a week, these samples were taken out from the water bath, water was wiped off by tissue paper on both sides of the surfaces and they were reweighed. Again, these test samples were reimmersed in the water bath. Furthermore, a detailed study for the effect of moisture absorption behaviour on the mechanical properties of basalt-fibre-reinforced polymer composites was performed by Pandian et al [46]. In this experimental work, the composites samples contained woven basalt, short basalt and alkaliand acid-treated basalt fibres. Next, water absorption tests were conducted by immersing specimens in water at room temperature for different time periods till they reached their saturation state. The tensile, flexural and impact properties of water-immersed specimens were determined and compared to those of dry samples as per the ASTM standard. Finally, Pan and Zhong [47] introduced a novel micromechanical model for predicting the overall mechanical degradation of naturalfibre-reinforced composites induced by moisture absorption. The natural fibre is hydrophilic in the humid environment with remarkable swelling deformation and mechanical degradation, which can be described by a damage variable. By means of a modified Mori-Tanaka method with a damage variable, the modulus loss of the composites was obtained. The theoretical predictions are in good agreement with experimental results, where the sisal fibres were formulated as randomly oriented straight inhomogeneities with a circular cylindrical shape. Further numerical examples for unidirectionalcircular-cylindrical-fibrer-reinforced composites show that a stiffer matrix can suppress the moisture absorption and the mechanical degradation of the composites, which suggests an effective way to reduce the overall mechanical degradation of the composite.

In this paper, the action of moisture absorption on the flexural properties of composites consisting of epoxy resin reinforced with low-content iron particles at ambient temperature was investigated as a continuation of this research field. The variation of flexural stress, flexural strain, maximum deflection, elastic modulus and Poisson ratio was examined, since it is known that the weak points of the particulate composites are mainly these aforementioned properties. 


\section{Theoretical considerations}

The density $\rho$ of a composite material can be theoretically evaluated by the rule of mixtures as follows:

$$
\rho_{\mathrm{c}}=\rho_{\mathrm{f}} U_{\mathrm{f}}+\rho_{\mathrm{m}} U_{\mathrm{m}},
$$

where the terms $\rho_{\mathrm{c}}, \rho_{\mathrm{f}}, \rho_{\mathrm{m}}$ denote the composite, filler and matrix density, respectively, and $U_{\mathrm{f}}, U_{\mathrm{m}}$ denote filler and matrix volume fraction.

The per-cent moisture content $M(t)$ of the composite or per-cent weight gain may be defined as the difference in weights of the moist $W_{\mathrm{m}}$ and dry $W_{\mathrm{d}}$ materials, normalized to $W_{\mathrm{d}}$, according to the following relationship:

$$
M(t)=\frac{W_{\mathrm{m}}-W_{\mathrm{d}}}{W_{\mathrm{d}}} \times 100 \% .
$$

A series of measurements of moisture content of sample materials was carried out at various time intervals.

In order to verify the validity of the respective Fickian diffusion theory [18], the experimental values of $M=f(t)$ were used to estimate the diffusivity $D$ of the material for various rates of $U_{\mathrm{f}}$ in a direction perpendicular to the lateral faces of the samples, which was determined by the following equation [18]:

$$
D=\pi\left(\frac{h}{4 M_{\mathrm{m}}}\right)\left(\frac{M_{2}-M_{1}}{\sqrt{t_{2}}-\sqrt{t_{1}}}\right)^{2},
$$

where the term $h$ is the thickness of the sample, $M_{\mathrm{m}}$ is the maximum moisture content for each case and the quantities $M_{i}, i=1,2,3$ are the moisture content at discrete times $t_{i}$ sequentially.

The values of diffusivity $D$ determined via Eq. (3) can be inserted in the following equation to obtain the timedependent coefficient $G(t)$ :

$$
G(t)=1-\exp \left(-7.3\left(\frac{D t}{s^{2}}\right)\right),
$$

where the term $s$ is the thickness of specimen for samples exposed on both sides to the same environment, while it is equal to $2 \mathrm{~h}$ for samples insulated on one of their faces.

The values of the time-dependent coefficient may now be substituted back into the simple relation expressing the instantaneous value of the moisture content of the composite material during both absorption and desorption according to diffusion theory developed [18]:

$$
M=G\left(M_{\mathrm{m}}-M_{i}\right)-M_{i},
$$

where the term $M_{i}$ now denotes the initial moisture content of the sample and $M(t)$ is the percent moisture content of the composite.

\section{Experimental}

\subsection{Materials, tests and experimental layout}

The devices and instruments that have been used to carry out the experiments are located in Strength of Materials Lab of NTUA and are briefly described as follows.

As can be seen in figure 1, a bath device that is appropriate for maintaining a constant-temperature environment till $120^{\circ} \mathrm{C}$, in which the specimens are soaked in distilled water and has been lent to the authors by the Water Analysis Lab of Chemical Engineering School of NTUA, has been mobilized in order to conduct the procedure of hydro-absorption.

A thermoscale of company type Kern RH 120-3 with an accuracy of $\pm 0.001 \mathrm{~g}$, where the specimens were placed to measure the weight change of samples during hydroabsorption, can be seen in figure 2. The thermoscale was used in the drying process of the samples at $80^{\circ} \mathrm{C}$. The instrument contains a special device to print the results of specimen weight reduction.

The thermomechanical properties of the constituent materials are presented in table 1.

The specimens used in this work have as matrix a system based on a diglycidil ether of bisphenol A (DGEBA) resin (Epikote 828) as prepolymer, with an epoxy equivalent of 185-192, a molecular weight between 370 and 384 and a viscosity of $15000 \mathrm{cP}$ at $25^{\circ} \mathrm{C}$.

As a curing agent, $8 \%$ triethylenetramine hardener (TETA) per weight of the epoxy resin was employed. The epoxy matrix was filled with iron particles with average diameter of $150 \mu \mathrm{m}$. The thermomechanical behaviour of the same composite materials was previously investigated $[12,13]$, while the effect of the water absorption at ambient temperature on their tensile properties was also examined in a series of previous publications $[23,24]$.

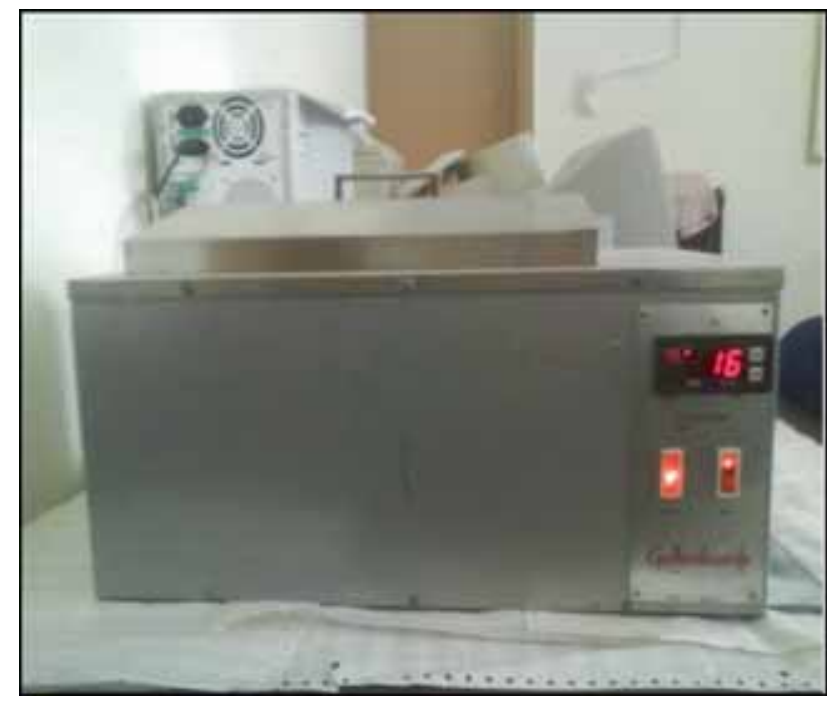

Figure 1. Device used for moisture experiments. 


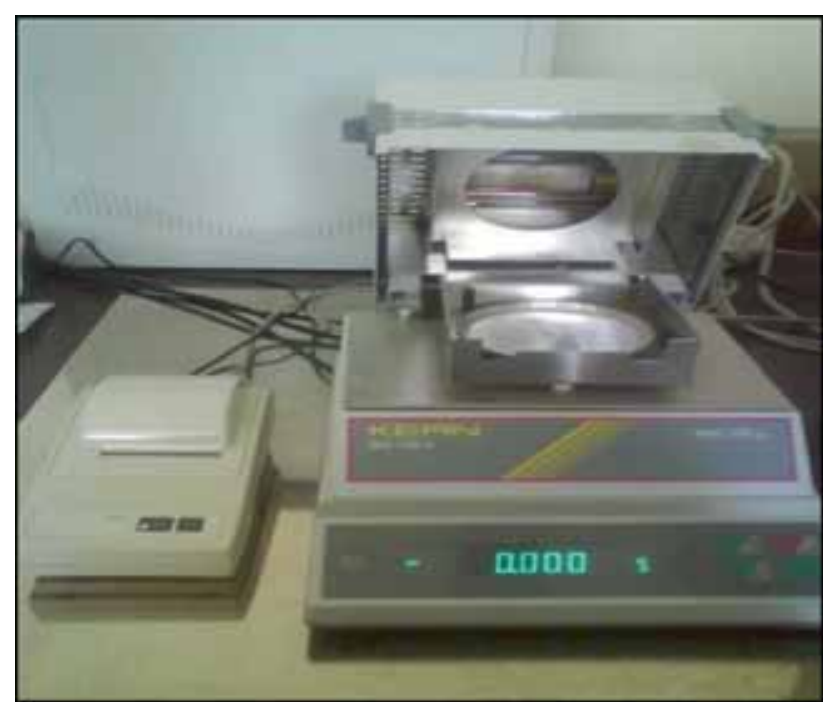

Figure 2. Device used for the measurements of moisture absorption.

Table 1. Thermomechanical properties of the constituent materials.

\begin{tabular}{lcc}
\hline Item & Epoxy resin & Iron \\
\hline Lame constants: & & \\
$\lambda(\mathrm{GPa})$ & 3.34 & 112 \\
$\mu(\mathrm{GPa})$ & 1.30 & 81 \\
Young's modulus, $E(\mathrm{GPa})$ & 3.53 & 210 \\
Bulk modulus, $K(\mathrm{GPa})$ & 4.21 & 167 \\
Poisson's ratio, $v$ & 0.36 & 0.29 \\
Density, $\rho\left(\mathrm{kg} \mathrm{m}{ }^{-3}\right)$ & $1.19 \mathrm{E} 3$ & $7.8 \mathrm{E} 3$ \\
Tensile strength $(\mathrm{MPa})$ & 65 & - \\
Coefficient of thermal & & \\
$\quad$ expansion $\left({ }^{\circ} \mathrm{C}^{-1}\right)$ & & -6 \\
$\quad<123$ & $65 \mathrm{E}-6$ & - \\
$\quad>123$ & $168 \mathrm{E}-6$ & -6 \\
Glass transition temperature, & 123 & \\
$\quad T_{\mathrm{g}}\left({ }^{\circ} \mathrm{C}\right)$ & & \\
\hline
\end{tabular}

The materials were produced as follows. The prepolymer was treated up to $30^{\circ} \mathrm{C}$ to decrease viscosity; proper amounts of curing agent and $150 \mu \mathrm{m}$ metal (iron) powder were subsequently added and the mixture, after being stirred thoroughly, was put in a vacuum cleaner for about $15 \mathrm{~min}$ for degassing. Later, it was cast into a rectangular plexiglas mould of suitable form and capacity with dimensions $\left(250 \times 10^{-3}\right) \times\left(150 \times 10^{-3}\right) \times\left(10 \times 10^{-3}\right) \mathrm{m}^{3}$ and coated with silicon oil to prevent adhesion of the mixture. The latter was then sealed so that it was possible to rotate it in space in order to prevent the settling of iron powder and to obtain as uniform a final product as possible. Pot life of the matrix material at the ambient temperature of $20^{\circ} \mathrm{C}$ was slightly decreased by the presence of the particles; it only took $20-25 \mathrm{~min}$ for the mixture to gel, after which no more rotating was necessary. The moulding was removed $24 \mathrm{~h}$ later and the casting was subjected to thermal processing, consisting of a temperature rise at $5^{\circ} \mathrm{Ch}^{-1}$, maintained constant at $100^{\circ} \mathrm{C}$ and finally dropped to ambient at $1^{\circ} \mathrm{Ch}^{-1}$.

In this manner, complete polymerization of the matrix material was obtained and consequently the properties of the final product did not exhibit any storage dependence. The test pieces, which had prismatic shape, were machined from each casting with dimensions of $190 \times 13 \times 10 \mathrm{~mm}^{3}$, according to ASTM D 790. The density was measured by weighting specimens of known volume and compared to theoretical values given by Eq. (1). For the percent weight change due to moisture absorption, according to ASTM D 570, before placing the test specimens into the waterbath they were dried in an oven at $50^{\circ} \mathrm{C}$, until their weight loss was stabilized. The dried specimens were then placed in a high vacuum for $24 \mathrm{~h}$ to create fully dried specimens and their weights were measured in an analytical balance. Next, the specimens were immersed in a distilled water bath at the constant temperature of $20^{\circ} \mathrm{C}$; changes in temperature were controlled to less than $\pm 0.5^{\circ} \mathrm{C}$. The specimens conditioned in water were then removed periodically, wiped, air dried for $5 \mathrm{~min}$ and then weighed. In order to measure the fracture stress, fracture strain, elastic modulus and Poison's ratio of the particulate composite in comparison to the corresponding features of matrix material, four-point bending experiments were carried out with an Instron-type testing machine at room temperature. Four specimens of each material were tested at a crosshead rate of $2 \mathrm{~mm} \mathrm{~min}^{-1}$.

In order to obtain the load-strain diagrams for each material, strain gauges (KYOWA type, gauge factor $k=1.99$, gauge length $(I)=2 \mathrm{~mm})$ were used.

In table 2, the type, size and shape of the samples are illustrated.

\subsection{Data presentation}

The strain was calculated with the aid of the following relationship:

$$
\varepsilon=\frac{2 \mu \cdot 10^{-6}}{k}
$$

Table 2. Specimen characteristics.

\begin{tabular}{lcccc}
\hline Type of specimens & Shape of specimens & Length (mm) & Width (mm) & Thickness (mm) \\
\hline $\begin{array}{l}\text { DGEBA epoxy resin: } \\
\text { Iron-particle-filled epoxy resin }\end{array}$ & Prismatic & 190 & 13 & 10 \\
\hline
\end{tabular}


where $\mu$ is the digital converter reading and $k$ the gauge factor.

The maximum normal stress in the outer fibres occurs between the two central loading points that define the load span. This stress can be calculated for any point on the loaddeflection curve by

$$
\sigma_{\max }=\frac{P L}{b d^{2}},
$$

where $P$ is the load at a given point in this region, $b$ the width of the beam and $d$ its thickness.

The flexural strength is equal to the maximum stress in the outer fibres at the moment of fracture. It is calculated using Eq. (7) by setting the variable $P$ equal to the load at the moment of fracture, i.e.,

$$
\sigma_{\mathrm{F}}=\frac{P_{\mathrm{F}} L}{b d^{2}}
$$

where $\sigma_{\mathrm{F}}$ is the stress at failure and $P_{\mathrm{F}}$ is the fracture load.

The maximum strain at the outer fibres may be calculated as follows:

$$
\varepsilon_{\max }=\frac{4.70 f_{\max }}{L^{2}} d
$$

where $f_{\max }$ denotes the maximum deflection of the centre of the beam at the moment of fracture.

The tangent modulus of elasticity is the ratio within the elastic limit of stress to corresponding strain and can be calculated by drawing a tangent to the steepest initial straight line portion of the load deflection curve as follows:

$$
E_{\mathrm{B}}=\frac{0.21 L^{3} m}{b d^{3}}
$$

where $E_{\mathrm{B}}$ is the tangent modulus of elasticity in bending and $m$ the slope of the tangent to the initial straight line portion of the load-deflection curve.

\section{Results and discussion}

It may be said that the influence of absorbed water molecules on the mechanical properties of polymers may either be harmful or beneficial. The enhancement of the mechanical properties can be attributed to the increased mobility of the polymer chains due to absorbed water molecules, which results in an orientation of polymer chains in the direction of applied stress. The arising question is that under what conditions water results in a degradation or in an enhancement of the mechanical properties. Figure 3 presents the variation of the composite density $\rho_{\mathrm{c}}$ with respect to the filler content, which is calculated according to the theoretical expression given by Eq. (1), along with the experimentally measured values. As these two sets of values of density are in good agreement, it

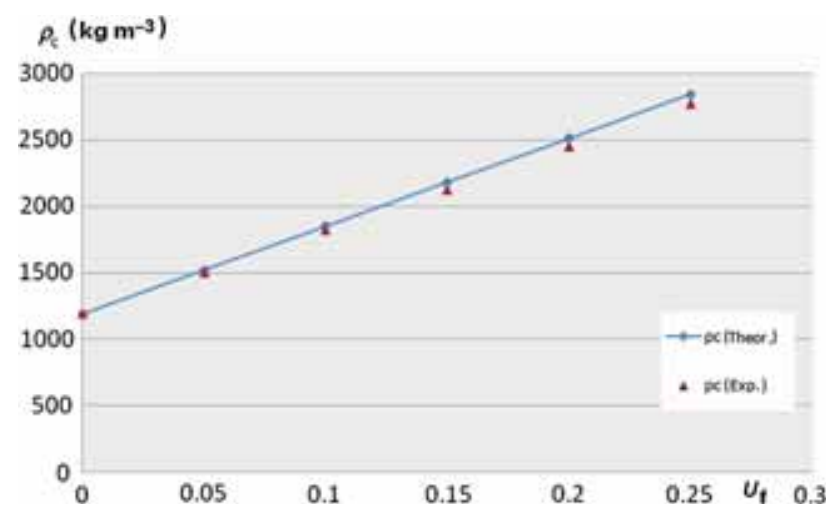

Figure 3. Density of the composite vs. filler content.
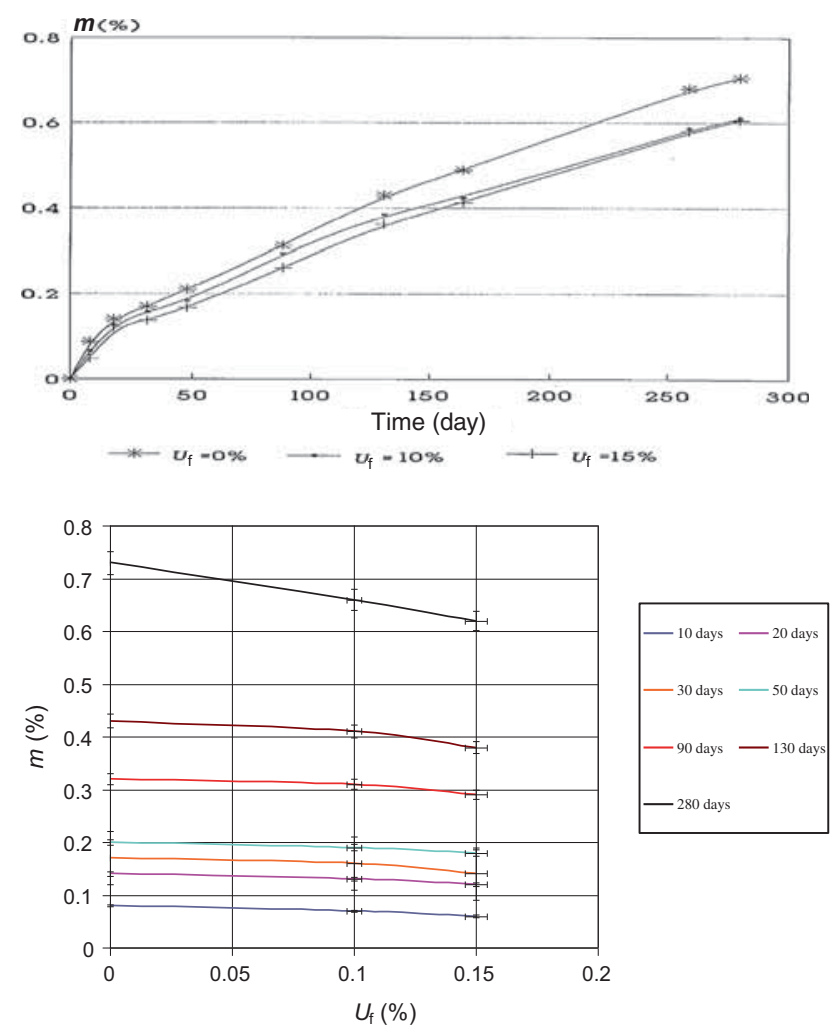

Figure 4. Moisture absorption vs. (a) time and (b) filler content.

is evident that no appreciable voids exist in the mass of the composite specimens.

The experimental data of moisture content for various values of the filler content $U_{\mathrm{f}}$ with respect to time, which were calculated using Eq. (2), are plotted in figure 4a. Each of these data points corresponds to the average value of four specimens. The values of $M$ determined using Eq. (5) are also plotted in the same figure by continuous lines. It can be observed that there is a satisfactory coincidence between theoretical and experimental values, indicating the validity of the theory. 
Table 3. Moisture absorption with respect to time for three classes of specimens.

\begin{tabular}{|c|c|c|c|c|c|c|c|c|}
\hline \multirow[b]{2}{*}{$U_{\mathrm{f}}$} & \multicolumn{8}{|c|}{$m(\%)$} \\
\hline & 0 day & 10 days & 20 days & 30 days & 50 days & 90 days & 130 days & 280 days \\
\hline \multirow[t]{6}{*}{0} & 0 & 0.08 & 0.13 & 0.17 & 0.20 & 0.29 & 0.43 & 0.71 \\
\hline & 0 & 0.09 & 0.15 & 0.18 & 0.22 & 0.32 & 0.44 & 0.73 \\
\hline & 0 & 0.09 & 0.14 & 0.17 & 0.21 & 0.35 & 0.43 & 0.71 \\
\hline & 0 & 0.1 & 0.15 & 0.17 & 0.22 & 0.31 & 0.46 & 0.75 \\
\hline & 0 & 0.08 & 0.14 & 0.17 & 0.21 & 0.32 & 0.43 & 0.71 \\
\hline & 0 & 0.06 & 0.14 & 0.16 & 0.20 & 0.31 & 0.43 & 0.74 \\
\hline \multirow[t]{6}{*}{0.1} & 0 & 0.09 & 0.13 & 0.15 & 0.19 & 0.29 & 0.42 & 0.71 \\
\hline & 0 & 0.08 & 0.14 & 0.17 & 0.21 & 0.32 & 0.42 & 0.72 \\
\hline & 0 & 0.07 & 0.13 & 0.16 & 0.20 & 0.33 & 0.41 & 0.71 \\
\hline & 0 & 0.06 & 0.12 & 0.15 & 0.21 & 0.31 & 0.44 & 0.73 \\
\hline & 0 & 0.07 & 0.12 & 0.17 & 0.20 & 0.32 & 0.43 & 0.71 \\
\hline & 0 & 0.08 & 0.13 & 0.16 & 0.19 & 0.31 & 0.42 & 0.72 \\
\hline \multirow[t]{6}{*}{0.15} & 0 & 0.08 & 0.12 & 0.14 & 0.18 & 0.27 & 0.41 & 0.70 \\
\hline & 0 & 0.07 & 0.13 & 0.16 & 0.20 & 0.32 & 0.42 & 0.72 \\
\hline & 0 & 0.06 & 0.11 & 0.17 & 0.19 & 0.31 & 0.40 & 0.71 \\
\hline & 0 & 0.05 & 0.12 & 0.13 & 0.21 & 0.31 & 0.42 & 0.70 \\
\hline & 0 & 0.06 & 0.11 & 0.15 & 0.19 & 0.32 & 0.43 & 0.71 \\
\hline & 0 & 0.07 & 0.13 & 0.16 & 0.17 & 0.31 & 0.41 & 0.70 \\
\hline
\end{tabular}

From the shapes of isothermal absorption curves plotted in figure 4 one may observe that initially each one of them is linear with time up to $0.15 \%$ weight gain and this suggests that in this initial time interval the absorption process constitutes a controlled diffusion. However, as time proceeds, the specimens are filled with moisture, leading to a decrease in moisture absorption rate after the formation of a slight cusp in the diagram. As the equilibrium moisture content is approached there is a slight decrease in the absorption rate at about $t=150$ days, but the equilibrium is not achieved even after 280 days. Such an anomalous behaviour has been also reported for other polymer diluents systems $[48,49,51]$. A thorough explanation of this kind of behaviour was given by Appicela et al [52], according to which the anomalous behaviour shown in highly humid environments could, in principle, be due to an effective concentration dependence of the diffusion coefficients.

Moreover, any damage induced in the epoxy resin, or epoxy composite, can cause deviations from the Fickian diffusion and accelerate moisture absorption. As to the influence of the filler content on the moisture absorption behaviour, one may note from figure $4 \mathrm{a}$ that as $U_{\mathrm{f}}$ increases the absorbed moisture decreases and also the linear variation of weight gain with respect to time slides to lower values. This may be explained by a 'transport model' for systems in which sorbed molecules can be divided into two populations, one formed by completely immobilized molecules and the other by freely diffusing molecules [30]. Also, it is known that as the filler content increases, the free volume decreases and the equilibrium is reached faster.
In table 3 the moisture content with respect to time for three classes of specimens with filler content of $0,0.1,0.15$ is presented. Each class contains six samples. Thus, in figure $4 \mathrm{~b}$ the variation of moisture absorption against filler volume fraction is illustrated for different times, i.e., 10-280 days.

On the other hand, the area surrounding each one of the inclusions as previously stated is characterized by voids, microcracks and other defects, which result in an anomalous moisture absorption behaviour. Since this kind of irregularities is more pronounced for high filler contents, it is reasonable to assume that at high filler volume fractions the behaviour will be more anomalous. Another explanation could be that moisture initially enters rapidly into the specimen, filling the microcracks that exist on the surface and inside the material [53]. However, after a few hours of exposure to the moisture, resin particles are actually lost into the water. Thus, there is a simultaneous loss of material and a weight gain due to the moisture absorption. The weight of the specimen increases if the weight gain is greater than the material loss, whereas in the opposite case, the weight of the specimen decreases. As a result of this mechanism, the measured weight change of the specimen does not always correspond to the moisture content of the material. At this point, it should be also emphasized that such a behaviour is more pronounced at high temperatures. Impurities in fluids or differences in material composition may also contribute to the differences in the weight change [54].

In figure $5 \mathrm{a}-\mathrm{c}$ the stress-strain diagrams of the particulate composite for $U_{\mathrm{f}}=0,0.10$ and 0.15 are illustrated for normal conditions, i.e., without moisture absorption, after 

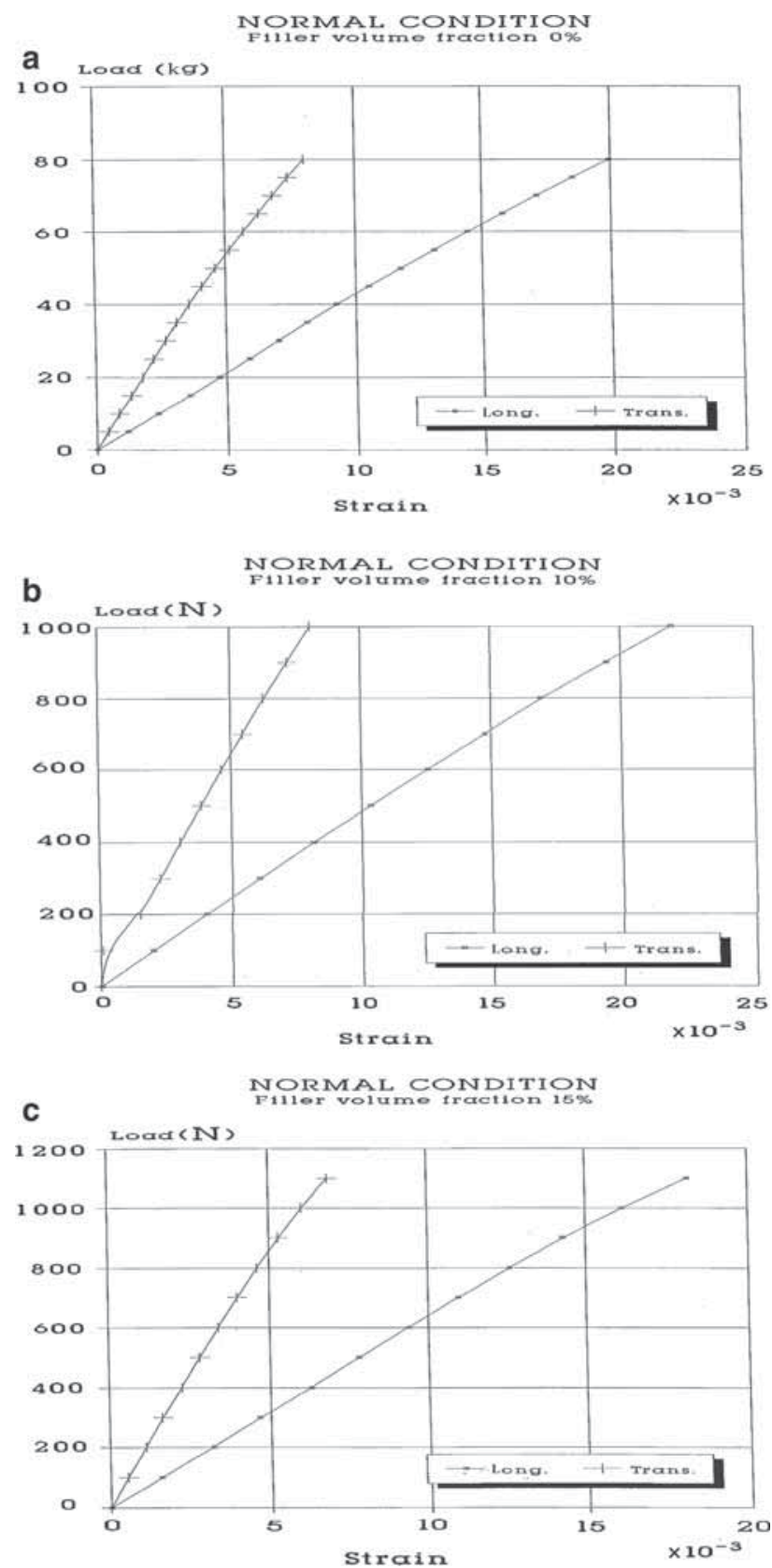

Figure 5. (a-c) Stress-strain diagrams for normal conditions at different filler contents.

bending experiments. Similarly, in figure $6 a-c$ the same diagrams appear for 280 days, i.e., for almost moisture saturation conditions. In these two series both longitudinal and transverse strains are traced in order to obtain the elastic modulus and the Poisson ratio of the material. It can be observed that the addition of iron particles decreases the elastic modulus of the material as the slope of the load vs. longitudinal strain curve diminishes, in all cases. As is well known when water is absorbed by a polymeric material, hydrogen bonds of hydroxyl group are broken, resulting in an increased segmental motion, i.e., rotation of chain segments. Moreover,
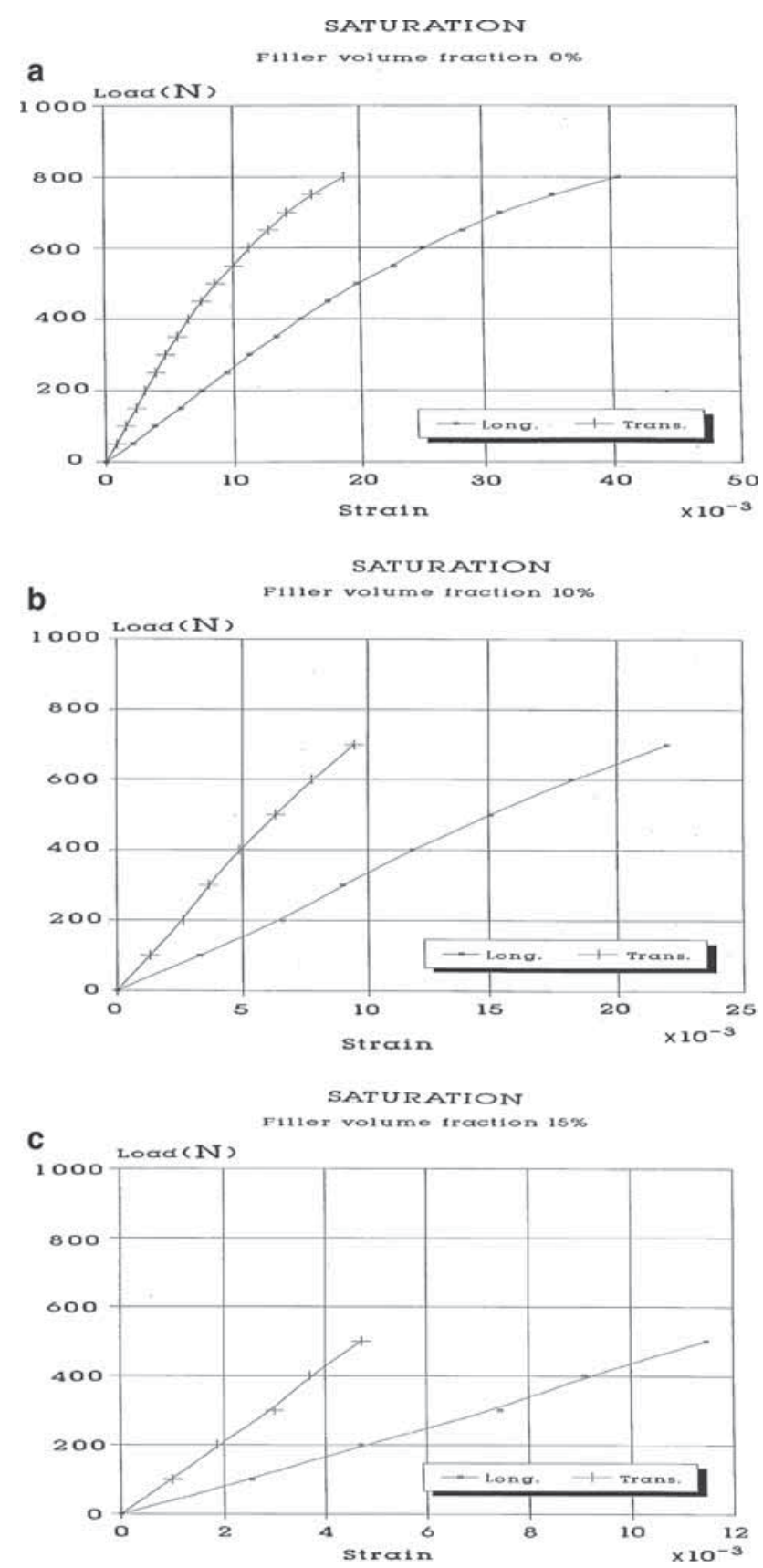

Figure 6. (a-c) Stress-strain diagrams for saturation conditions at different filler contents.

due to the migration of water molecules from one group to another, small amounts of water may have a large effect on the mechanical properties of the material. A point that is worth mentioning is that the addition of the filler influences the material and renders the matrix less ductile as can be observed from the more linear behaviour of the strain curves, especially in the moisture saturation conditions.

In figure $7 \mathrm{a}-\mathrm{c}$ the flexural stress at failure $v s$. filler content is illustrated for normal conditions (without moisture absorption) and for 110 and 280 days of moisture absorption, i.e., 

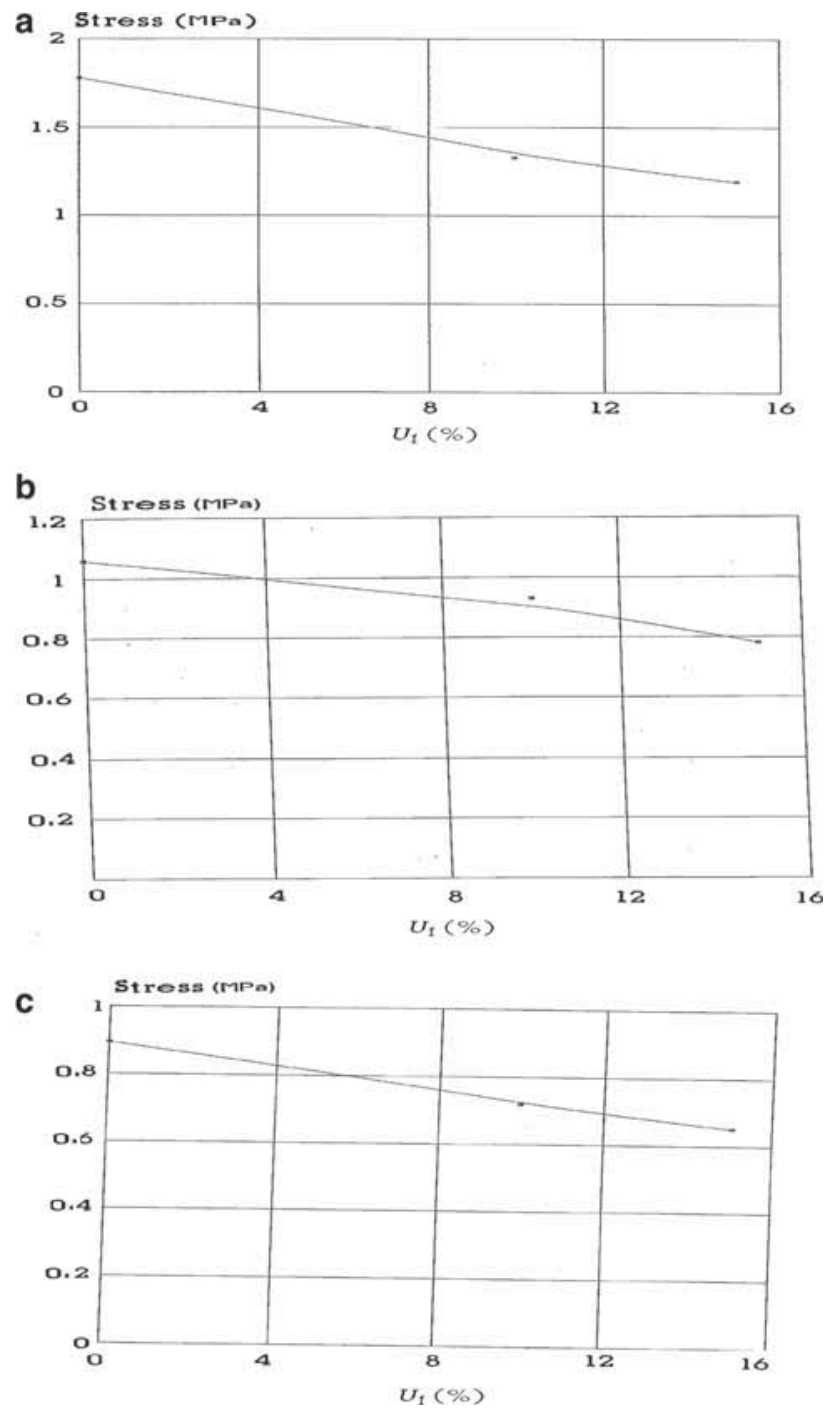

Figure 7. $(\mathbf{a}-\mathbf{c})$ Flexural stress at failure $v s$. filler content.

for almost moisture saturation conditions, respectively. In all cases the stress decreases as filler is added in the matrix material. This means that the addition of iron particles diminishes the stress at failure as well as the ductility of the material. Residual stresses due to swelling and eventual interface degradation due to moisture are mechanisms that possibly induce the flexural stress at failure loss. These mechanisms are most prevalent at room temperature, where the composite is more brittle.

In figure 8 the variation of elastic modulus vs. the filler volume fraction is illustrated. It can be clearly observed that, as stated previously, the modulus increases when iron particles are uniformly added in the epoxy resin matrix and also this modulus decreases as it is exposed more to moisture absorption. It is well known that absorbed moisture causes a reduction of the composite modulus similar to that of the matrix. However, the decrease is more severe for the matrix

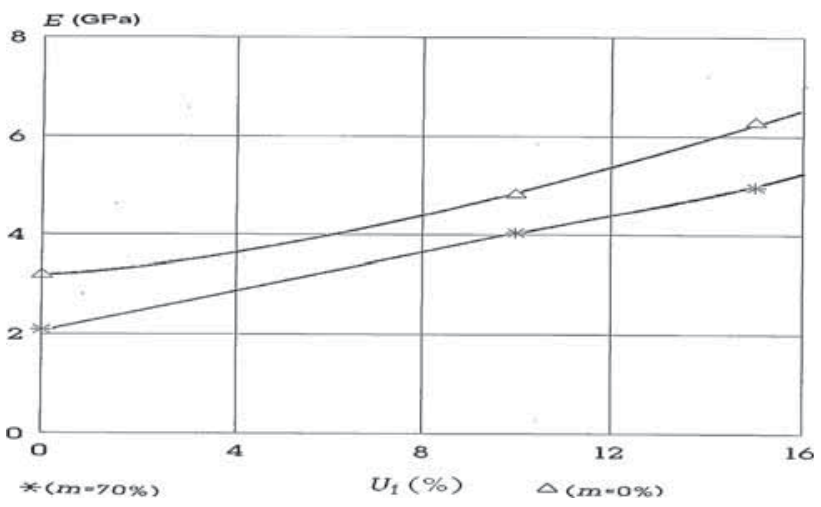

Figure 8. Variation of elastic modulus vs. filler content.
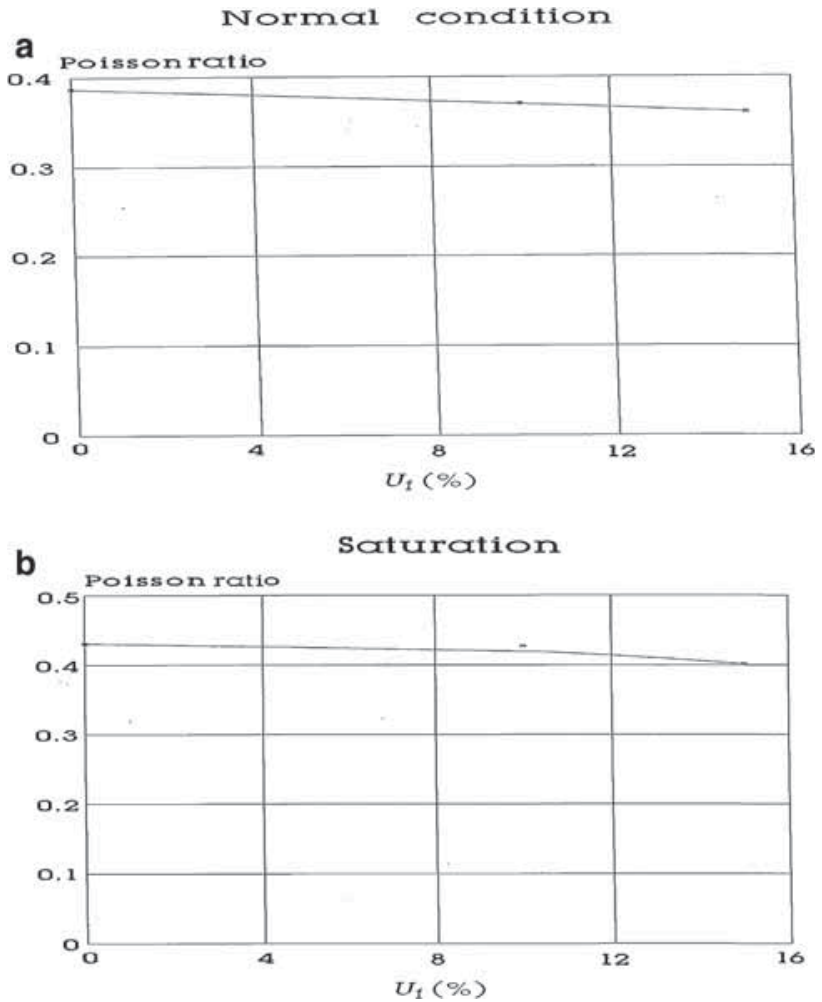

Figure 9. (a and $\mathbf{b})$ Variation of Poisson ratio vs. filler content.

than for the composite, as can be observed from this figure. In figure $9 \mathrm{a}$ and $\mathrm{b}$ the variation of the Poisson ratio $v s$. filler content is presented for normal conditions and for moisture saturation conditions, respectively. It can be explicitly observed that the Poisson ratio decreases as the filler volume fraction increases and the moisture absorption raises this elastic constant. This may be due to the following phenomenon. It has been noted that an increase in the moisture content of the polymers reduces their glass transition temperature $T_{\mathrm{g}}$, which is a measure of their flexibility. The lower this value the greater their flexibility. Thus, in a composite the moisture effects are limited to the permeable phase, i.e., the resin, whose flexibility increases as the moisture content is increased; this effect, 


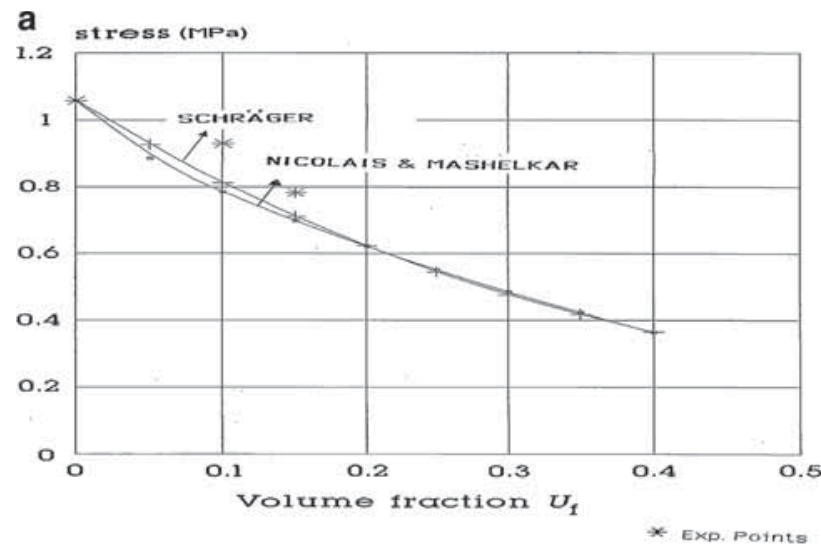

b

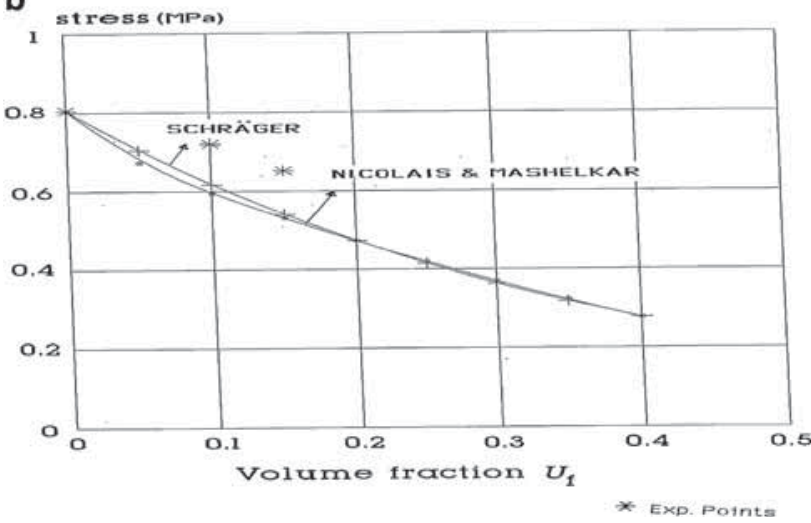

Figure 10. Variation of stress at failure $v s$. filler content for (a) 110 and (b) 280 days.

however, is reflected in an overall increase in the value of Poisson ratio of the composite.

Comparison of the experimental results for flexural stress at failure versus filler content for 110 and 280 days of moisture absorption with theoretical values obtained by Eqs. (11) and (12) of Schrager [55] and Nicolais and Mashelkar [56], respectively, is illustrated in figure 10a and b. It can be observed that there is a difference of about $10 \%$ between theoretical and experimental values in both cases. Comparison of the experimental results for flexural strain at failure $v s$. filler volume fraction for saturation moisture conditions with theoretical values obtained by Eqs. (13) and (15) of Smith [57], Bueche [58] and Ziegel et al [59], respectively, is presented in figure 11. It can be undoubtedly observed that there exists a slight discrepancy between the experimental results and theoretical results of Bueche and Smith and a total disaccord with those of Ziegel et al, who assume an almost linear variation instead of a curve.

Load-deflection diagrams for various filler contents are illustrated in figure 12a-c for normal conditions and for moisture saturation conditions in figure 13a-c. It can be observed that the deflections at the middle of the specimens decrease as the epoxy resin is uniformly enhanced by iron particles, in both cases. On the other hand it can be said that the moisture absorption almost does not affect the deflection for each case of particle content since the respective values when compared

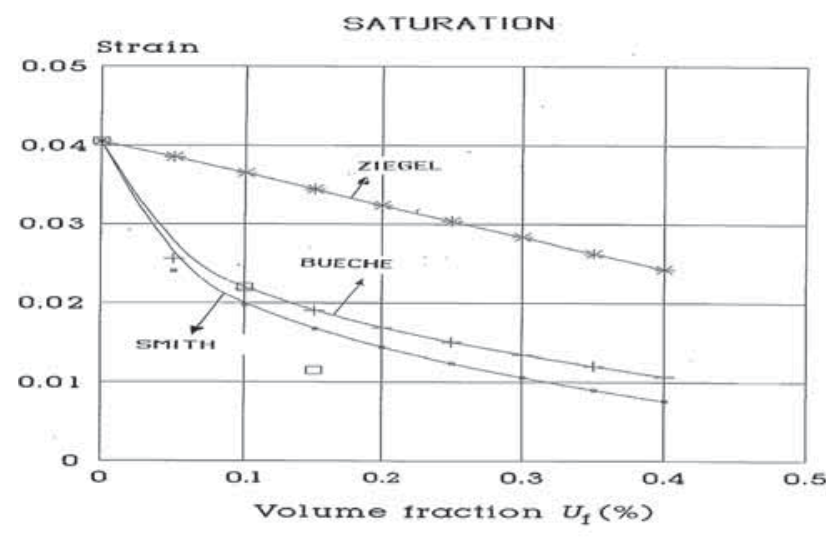

DExp. Point:

Figure 11. Variation of failure strain $v$ s. filler content for 280 days.

to those obtained from dry specimens are too close. This can mainly attributed to the fact that the elastic modulus diminishes as the specimen is exposed to water. It is known that absorbed moisture causes a modulus reduction in parallel with a strength reduction in the composite, which are very similar to those of the matrix. However, the flexural strength loss is more severe for the composite than for the matrix and this is shown in figure 5, where the variation of elastic modulus is plotted $v s$. filler content. Residual stresses due to swelling and eventual surface degradation due to moisture are possible mechanisms that induce strength loss. The dependence of the fracture strain, the fracture stress as well as the elastic modulus on the time of immersion for different filler contents shows a general decrease as the time of immersion is increased, as may be anticipated. However, there does not seem to be a clear correlation between the losses in flexural strength and the weight change. Hence, a unique relationship between the weight change and the change of these mechanical properties cannot be readily established. An evaluation of the experimental results can yield the following interesting conclusion.

The degradation of the mechanical properties of ironparticle-reinforced epoxy composites due to moisture absorption is more pronounced after immersion for 110 days into water than after immersion for 280 days. This kind of behaviour is due to a combination of several parameters affecting the ultimate mechanical properties of composite materials. Amongst these parameters, one may consider the inhomogeneous distribution of the water molecules in the composite, resulting in craze initiation in the matrix and the formation of water clusters in the polymer. These phenomena may create preferentially high plasticized zones, which would lower local shear stresses and favour cavitations.

Moreover, during the preparation of the specimens, the particles may aggregate to form larger particles often containing holes. On the other hand, in areas where voids exist, these voids originate from holes in the original granular particles and form incomplete contacts amongst particles. These voids and holes formed in the polymeric matrix are 

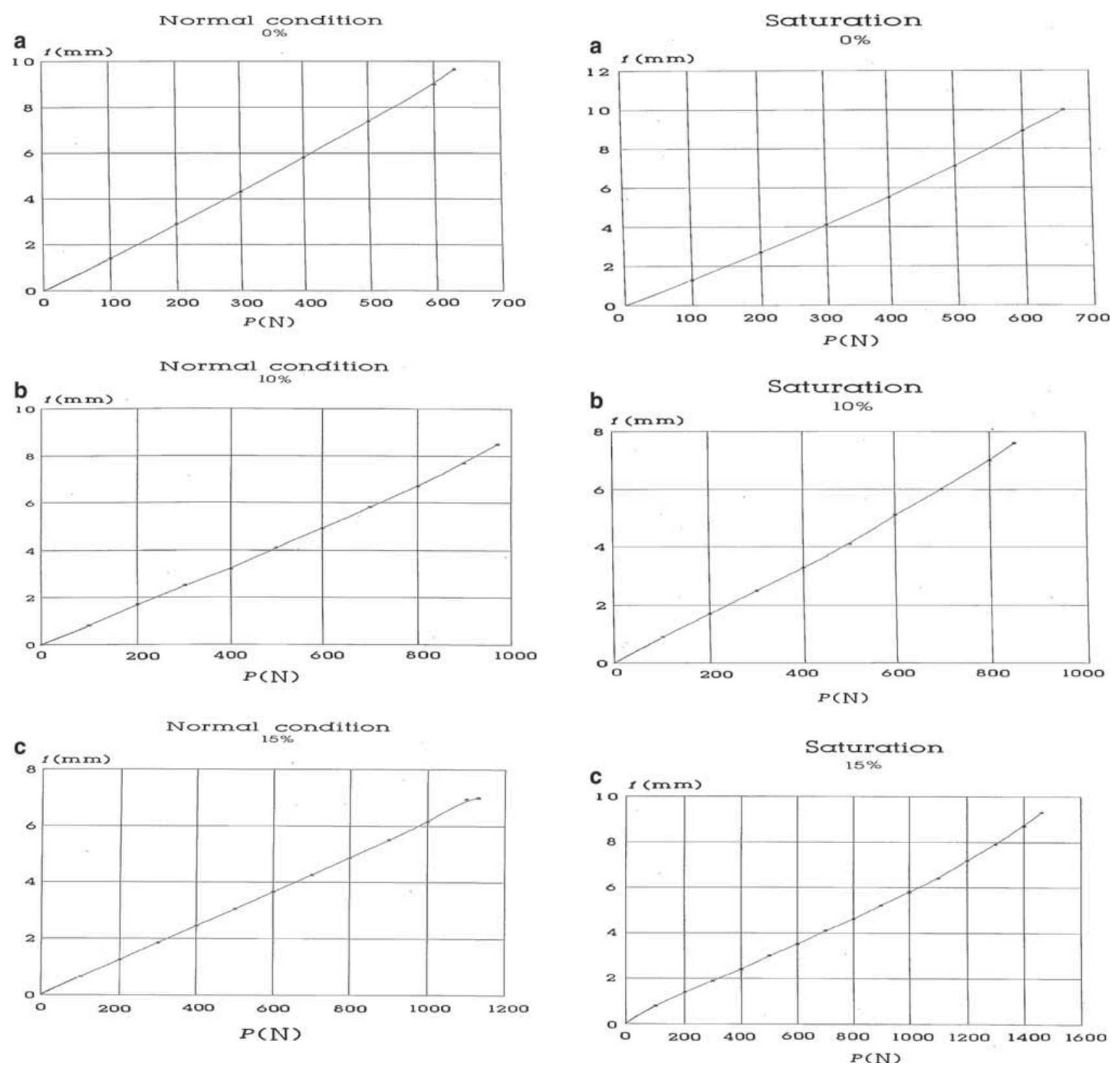

Figure 12. (a-c) Load-deflection diagrams for normal conditions.

Figure 13. (a-c) Load-deflection diagrams for saturation state.

of cardinal importance in determining the degradation of the mechanical response of composite specimens due to moisture absorption.

In figure 14a and $b$, photos of a specimen before failure during the four-point bending experiment and also the surface of fractured specimen are illustrated. The large deflection and the failure of the specimen in the first photo and the difference between the two zones or areas after fracture in the second photo, where one of the zones appears 'polished' whereas the second one seems rough, are noteworthy. Low degrees of damage characterize samples conditioned in water at ambient temperature when equilibrated in environments of different relative humidities.

Here, we can point out that the obtained results are not totally in accordance with those obtained from Galperin $e t$ al [60], who reported their observation that in the system Epoxy 828 with $14.3 \% \mathrm{TiO}_{2}$ the presence of humidity seems to enhance mechanical properties such as tensile strength, ultimate elongation and elastic modulus. On this point the following comments can be made. It is well known that absorbed moisture causes a modulus reduction as well as a strength reduction in the composite, which are very similar to those of the matrix. However, the strength loss is more severe for the composite than for the matrix. The dependence of the ultimate strain as well as the ultimate stress on the time of immersion for different filler contents is usually a decrease 
a

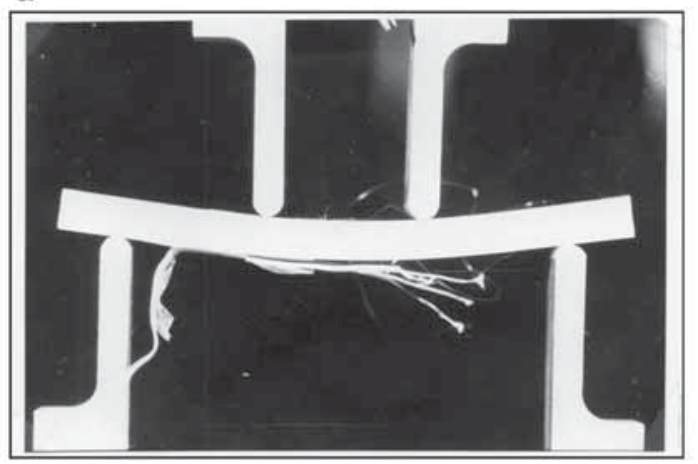

b

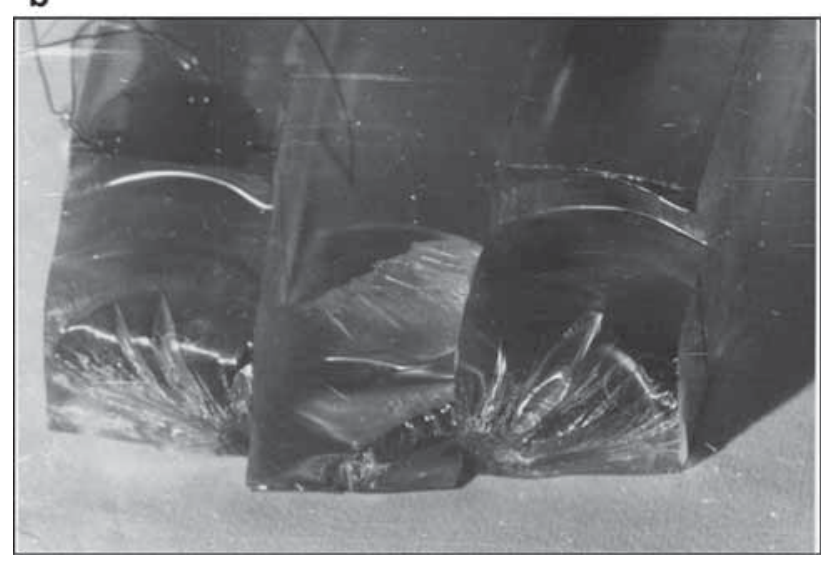

Figure 14. (a) Specimen under four-point bending and (b) fractured specimen.

when the time of water exposure is increased. The void content, the swelling, or the polymerization, the hardening and the curing of the matrix may be the reasons. The results of the aforementioned reference can be explained in this manner. Theocaris et al [24] observed a slight increase of the elastic modulus at the first period of immersion into water but this was followed by a subsequent decrease. In our work, only the flexural strain and deflection seem not to be significantly affected by water absorption; it cannot be said that these properties are enhanced by humidity, as claimed in Ref. [60].

The results of this experimental work are synopsized in table 4 , which shows a qualitative behaviour of the composite properties when filler content and moisture absorption are augmented.

\section{Conclusions}

A systematic investigation of the influence of water absorption on the flexural properties of low-content iron particle-epoxy composites was performed in this article. Ambient water conditioning temperature was used during this study, from which the following firm conclusions may be drawn.
Table 4. Influence of moisture absorption and filler content on composite flexural properties.

\begin{tabular}{lcc}
\hline Property & Particle content & Water absorption \\
\hline Flexural strength & Decrease & Decrease \\
Flexural strain & Decrease & Little difference \\
Flexural modulus & Increase & Decrease \\
Poisson ratio & Decrease & Increase \\
Deflection & Decrease & Little difference \\
\hline
\end{tabular}

(i) The equilibrium moisture volume fraction is approached faster as the filler concentration is increased.

(ii) An equilibrium was not achieved even after 280 days of moisture exposure.

(iii) The flexural strength, the flexural strain and the flexural modulus show in general a decrease, whereas Poisson ratio shows an increase, with the time of immersion.

(iv) The flexural strength, the flexural strain and the Poisson ratio decrease, whereas the elastic modulus increases, as the filler content is increased.

Finally, it can be said that the degradation of the mechanical properties of iron-particle-reinforced epoxy composites due to moisture absorption is more pronounced after immersion for 110 days into water than after immersion for 280 days. The plasticization and polymer-filler interface failure should play a role on the variation of the mechanical properties of the material.

Also, the results of an experimental research work carried out with particulate composites in hygrothermal conditions may be compared to experimental data that will be carried out with new materials in the future, whenever it is possible.

\section{Appendix}

\subsection{Tensile stress at failure}

Schrager formula [55]

$$
\sigma_{\mathrm{c}}=\sigma_{\mathrm{m}} e^{-r \cdot U_{\mathrm{f}}},
$$

where $\sigma_{\mathrm{c}}$ and $\sigma_{\mathrm{m}}$ denote the composite and the matrix stress at failure, respectively, and $r$ is a constant equal to 2.66, obtained from experiments

Nicolais-Mashelkar formula [56]

$$
\sigma_{\mathrm{c}}=\sigma_{\mathrm{m}}\left(1-1.21 U_{\mathrm{f}}^{2 / 3}\right) \text {. }
$$

\subsection{Tensile strain at failure}

Bueche-Nielsen formula [58]

$$
\varepsilon_{\mathrm{c}}=\varepsilon_{\mathrm{m}}\left(1-U_{\mathrm{f}}^{1 / 3}\right),
$$


where $\varepsilon_{\mathrm{m}}$ and $\varepsilon_{\mathrm{c}}$ denote the matrix and the composite strain at failure, respectively.

Ziegel formula [59]

$$
\varepsilon_{\mathrm{c}}=\varepsilon_{\mathrm{m}}\left[1-U_{\mathrm{f}}(1+\Delta r / R)^{3}\right],
$$

where $\Delta r$ is the increase of the radius $R$ of the particles due to existence of an interphase.

Smith formula [57]

$$
\varepsilon_{\mathrm{c}}=\varepsilon_{\mathrm{m}}\left(1-1.06 U_{\mathrm{f}}^{1 / 3}\right)
$$

\section{References}

[1] Mc Kague E L, Reynolds J D and Halkias J E 1975 Life Assur. Compos. Struct. AFML Tech. Rep. 151

[2] Fried N 1967 Proceedings of the fifth symposium on naval structural mechanics (Philadelphia: Pergamon Press) p 813

[3] Hertz J 1970 Proc. Soc. Aerospace Mater. Process Eng. 39

[4] Browning C E and Whitney J M 1974 Fillers and reinforcements for plastics, advances in chemistry series, No. 134 (USA: Amer. Chem. Soc.) p 137

[5] Browning C E and Hartness J T 1974 Proc. Third ASTM STP546 284

[6] Adamson M J 1980 J. Mater. Sci. 151736

[7] Landal R F and Smith T L 1961 Am. Rocket Soc. J. 31599

[8] Kwei T K and Kumins C A 1964 J. Appl. Polym. Sci. 81483

[9] Turner S 1965 Appl. Mat. Res.10 10

[10] Van Der Wal C W, Bree H W and Schwarzl F R 1965 J. Appl. Polym. Sci. 92145

[11] Kumins C A and Roterman J 1963 J. Polym. Sci. A: Polym. Chem. 1527

[12] Papanicolaou G C, Paipetis S A and Theocaris P S 1977 J. Appl. Polym. Sci. 21689

[13] Theocaris P S, Papanicolaou G C and Sideridis E P $1982 \mathrm{~J}$. Reinf. Plast. Compos. 150

[14] Strella S and Erhart P F 1969 J. Appl. Polym. Sci. 131373

[15] Morgan R J and O' Neal J E 1978 Polym. Plast. Technol. Eng. 10 49

[16] Manson J A and Chin E H 1973 J. Polym. Sci. C 1331654

[17] Mc Kague E L, Halkias J E and Reynolds J D 1975 J. Comput. Mater. 1049

[18] Shen C H and Springer G S 1976 J. Comput. Mater. 102

[19] Mehta B S, Dibenetto A T and Kardos J L 1977 J. Appl. Polym. Sci. 213111

[20] James D I, Norman R H and Stone M H 1968 Plastics Polym. 3621

[21] Ashbee K H, Frank F C and Wyatt R C 1967 Proc. R Soc. A 300 415

[22] Steel D J 1967 Trans. Plast. Inst. 35429

[23] Theocaris P S, Papanicolaou G C and Kontou E A 1983 J. Appl. Polym. Sci. 283145

[24] Theocaris P S, Kontou E A and Papanicolaou G C 1983 Colloid Polym. Sci. 261394
[25] Weitsman Y J and Guo Y J 2002 Compos. Sci. Technol.62 889

[26] Hiel C and Adamson M 1986 Compos. Struct. 6243

[27] Bera T, Mula S, Ray P K and Ray B C 2007 J. Reinf. Plast. Compos. 26725

[28] Blikstad M, Siöblom P O W and Johannesson T R $1984 \mathrm{~J}$. Compos. Mater. 1832

[29] Apicella A, Egiziano L, Nicolais L and Tucci V 1988 J. Mater. Sci. 23729

[30] Apicella A and Nicolais L 1981 Ind. Eng. Chem. Prod. Res. Dev. 20138

[31] Verpoest I and Springer G S 1988 J. Reinf. Plast. Compos. 72

[32] Cai L W and Neitsan Y 1994 J. Compos. Mater. 29130

[33] Woo M and Piggott M R 1987 J. Compos. Technol. Res. 9162

[34] Weitsman Y J 1987 Int. J. Solids Struct. 231003

[35] Xiang Z D and Jones F R 1997 Compos. Sci. Technol. 57451

[36] Park C H and McManus H L 1996 Compos. Sci. Technol. 56 1209

[37] Popineau S, Rondeau-Mouro C, Sulpice-Gaillet C and Shanahan M E R 2005 Polymer 4610733

[38] Ozdemir T and Mengeloglu F 2008 Int. J. Mol. Sci. 92559

[39] Athijayamania A, Thiruchitrambalamb M, Natarajana U and Pazhanivel B 2009 Mater. Sci. Eng. A 517344

[40] Fiorelli J, Curtoloa D, Barreroa N, Savastano Jr H, de Jesus Agnolon Pallonea E and Johnson R 2012 Ind. Crops Prod.40 69

[41] Tagliavia G, Porfiri M and Gupta N 2012 Composites Part B 43 115

[42] Singh A, Singh S and Kumar A 2013 Int. J. Mater. Sci. Appl. 2 157

[43] Bhaskar J and Singh V 2013 J. Mater. Environ. Sci. 4113

[44] Hamim S and Singh R 2014 Int. Scholarly Res. Notices 2014 Article ID 489453 doi:10.1155/2014/489453

[45] Hossain M R, Hossain M F and Islam M A 2014 J. Sci. Res. 6 431

[46] Pandian A, Vairavan M, Jappes W, Jebbas T and Uthayakumar M 2014 J. Compos. 2014 Article ID 587980

[47] Pan Y and Zhong Z 2015 Mech. Mater. 857

[48] Le Grand P G, Kambour R P and Haaf W R 1972 J. Polym. Sci. A2 1565

[49] Thomas N A and Windle H 1978 Polymer 19253

[50] Nicolais L E 1978 J. Membr. Sci. 3231

[51] Apicella A, Nicolais L, Astarita G and Drioli E 1981 Polym. Eng. Sci. 2118

[52] Apicella A, Nicolais L, Astarita G and Drioli E 1979 Polymer 201143

[53] Wieth W R and Sladek K J 1965 Colloid Sci. 201014

[54] Springer G C, Sanders B A and Tung R W 1980 J. Comput. Mater. 14213

[55] Schrager M 1978 J. Appl. Polym. Sci. 102379

[56] Nicolais L and Mashelkar R A 1976 J. Appl. Polym. Sci. 20 561

[57] Smith T L 1961 Rubber Chem. Technol. 34123

[58] Bueche F 1960 J. Appl. Polym. Sci. 4107

[59] Ziegel K D, Frensdorff H K and Fogiel A W 1969 J. Appl. Polym. Sci. 13867

[60] Galperin I, Arnheim W and Kwei T W 1965 J. Appl. Polym. Sci. 93215 